\title{
Opiate receptors in the brain
}

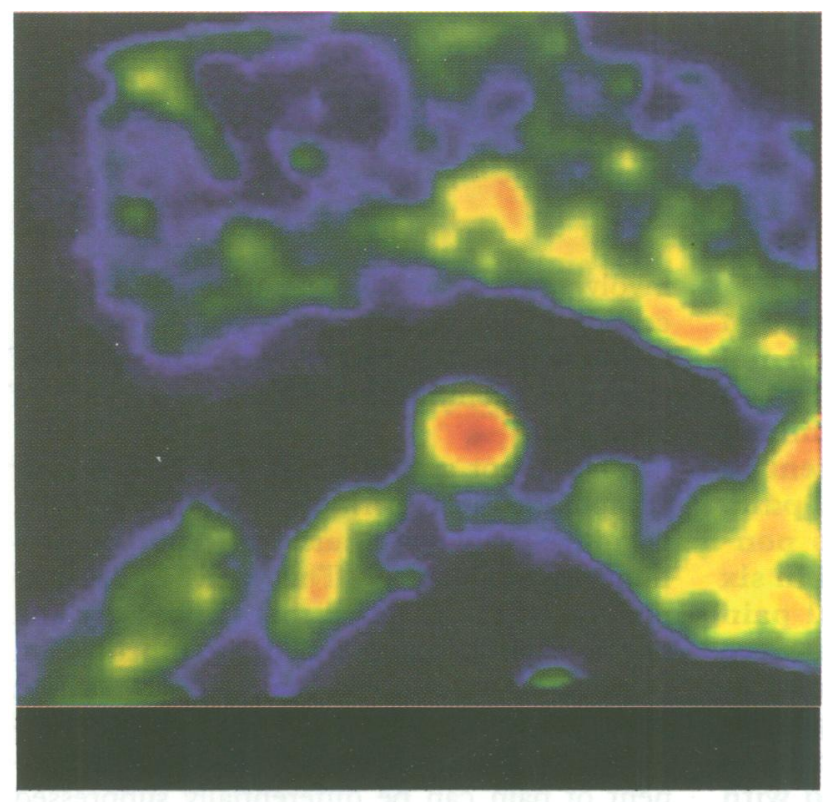

$A$

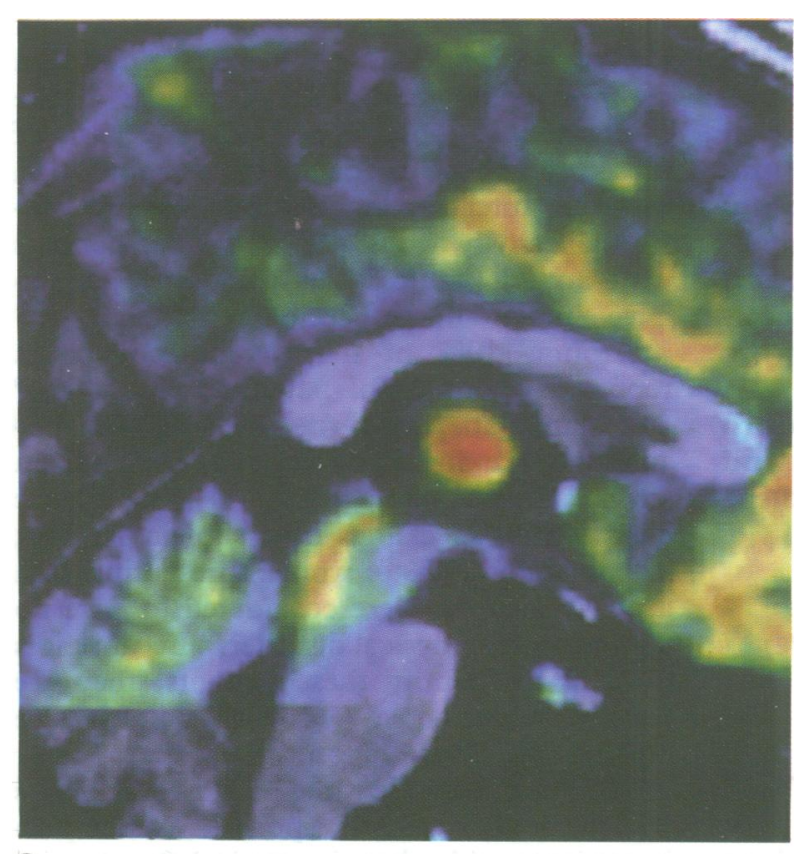

C

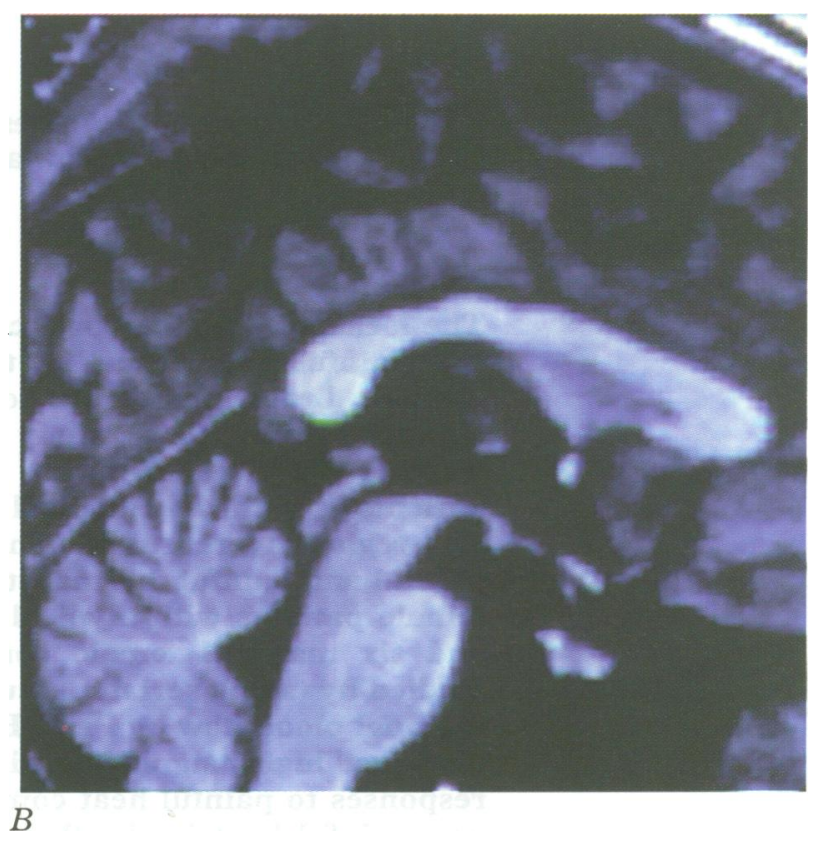

Distribution of opiate receptors imaged with ${ }^{11} \mathrm{C}$ diprenorphine in the human brain. (A), PET; (B), MRI; (C), coregistered images. The concentration of opiate receptors is maximal in the thalamus and is also high in the anterior parts of the cingulate cortex and in the periaqueductal grey matter in the brain stem.

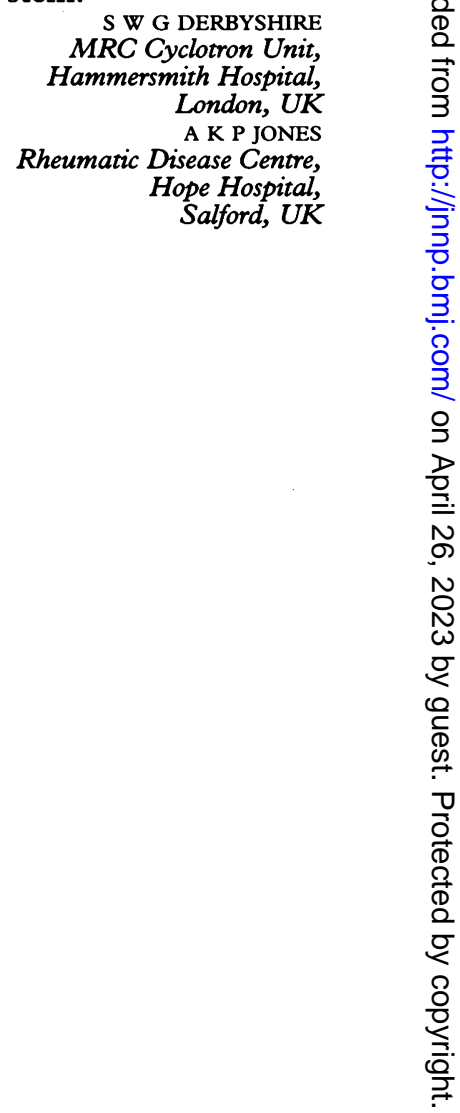

